\title{
Evidence That Release of Adenosine Triphosphate From Endothelial Cells During Increased Shear Stress Is Vesicular
}

\author{
Philippe Bodin and Geoffrey Burnstock
}

\author{
Autonomic Neuroscience Institute, Department of Anatomy and Developmental Biology, Royal Free and University \\ College Medical School, London, U.K.
}

\begin{abstract}
Summary: In response to increased shear stress, vascular endothelial cells release adenosine triphosphate (ATP) by an unknown mechanism. We have investigated this mechanism using different approaches. First, we discovered that quinacrine, used to locate intracellular stores of ATP bound to peptides, displayed a granular fluorescence, typical of vesicular storage. Second, we found that two inhibitors of vesicular transport (monensin and $\mathrm{N}$-ethylmaleimide) produced a highly significant reduction in the release of ATP from vascular endothelial cells in response to increased shear stress. Preliminary experiments using inhibitors of the cystic fibrosis transmembrane regulator, the sulfonylurea receptor, and the multidrug resistance protein showed no involvement of these ATP-binding cassette transporter proteins (previously characterized in endothelial cells) in the mechanism of release of ATP. We suggest, therefore, that the release of ATP from vascular endothelial cells, like that of nerve cells, is probably by vesicular exocytosis. Key Words: Endothelial cells-Quinacrine-Adenosine triphosphate transport-ExocytosisAdenosine triphosphate-binding cassette proteins.
\end{abstract}

Endothelial cells, in vivo, are constantly subjected to shear stress because of their location on the inside of the lumen of blood vessels and their contact with the circulating blood. Variation of the stress to endothelial cells leads to a wide range of responses including endocytosis, regulation of genes, morphologic changes, and release of vasoactive substances (1-3).

The release of adenosine triphosphate (ATP) from endothelial cells subjected to shear stress has already been demonstrated and characterized $(2,4)$. It has been shown that this release occurs from endothelial cells but not from vascular smooth muscle cells; it is transient, proportional to the amount of shear stress applied to the cells, and decreases rapidly following successive stimulations (4). However, the molecular mechanisms associated with ATP release are unknown.

Adenosine triphosphate release from nerve terminals appears to be vesicular (5) but there is growing realization that release from some non-neuronal cells may not be by exocytosis (6): ATP-binding cassette (ABC) proteins comprise a family of structurally related membrane proteins sharing a common intracellular motif that binds and hydrolyzes ATP (7). Although the functions of these proteins have not yet been elucidated, many of them are involved in the transport of highly polarized substrates across biologic membranes by using ATP to energize the
Received November 13, 2000; accepted June 25, 2001.

Address correspondence and reprint requests to Prof. G. Burnstock at Autonomic Neuroscience Institute, Royal Free and University Col- lege Medical School, Rowland Hill Street, London NW3 2PF, U.K. E-mail: g.burnstock@ucl.ac.uk 
translocation. There is evidence that direct (8) or indirect (9) ATP export across plasma membranes is associated with the presence of such proteins.

In this paper, we investigate the mechanism by which ATP is released from vascular endothelial cells under conditions of increased shear stress. We localized intracellular stores of ATP by using quinacrine and investigated the effects of monensin, an inhibitor of the formation of vesicles at the level of the Golgi apparatus (10), the effects of $N$-ethylmaleimide (NEM), an inhibitor of the fusion of vesicles to plasma membranes (11). In addition, we examine the effects of inhibitors on three $\mathrm{ABC}$ proteins previously identified in endothelial cells (1214): the cystic fibrosis transmembrane regulator (CFTR), the sulfonylurea receptor, and the multidrug resistance protein (MDR).

\section{METHODS}

\section{Cell cultures}

Umbilical cords from normal vaginal deliveries were processed and human umbilical vein endothelial cells (HUVECs) were harvested as previously described (15). Cells from primary cultures were used at confluence (3-4 days).

\section{Shear stress}

Endothelial cells were subjected to shear stress in sixwell plates using a cone and plate apparatus designed in our laboratory (16). Shear stresses of $10 \mathrm{dyn} / \mathrm{cm}^{2}(\sim 50$ $\mathrm{rpm})$ or $25 \mathrm{dyn} / \mathrm{cm}^{2}(\sim 120 \mathrm{rpm})$ were used throughout the study.

\section{Pretreatment of the cells}

Human umbilical vein endothelial cells were preincubated with either verapamil $\left(10^{-4}, 10^{-5}\right.$, and $\left.10^{-6} \mathrm{M}\right)$ or glibenclamide $\left(10^{-5}, 10^{-6}\right.$, and $\left.10^{-7} \mathrm{M}\right)$ for $30 \mathrm{~min}$, NEM $\left(10^{-5}\right.$ and $\left.10^{-6} M\right)$ for $15 \mathrm{~min}$, or monensin $\left(10^{-5} \mathrm{M}\right.$ and $10^{-4} \mathrm{M}$ ) for $60 \mathrm{~min}$ at $37^{\circ} \mathrm{C}$. Before all experiments, endothelial cells were rinsed several times with Dulbecco-phosphate-buffered saline (DPBS) supplemented with calcium $(0.13 \mathrm{~g} / \mathrm{l})$ and magnesium $(0.1 \mathrm{~g} / \mathrm{l})\left(\mathrm{DPBS}^{+}\right)$ (Sigma Chemical Co., St. Louis, MI). The wells were filled with $2 \mathrm{ml}$ of DPBS ${ }^{+}$, positioned on the cone and plate apparatus, and then stimulated by shear stress. The role of extracellular $\mathrm{Ca}^{2+}$ was investigated by incubating the cells in DPBS supplemented with $10 \mathrm{mM}$ of $\mathrm{MgCl}_{2}$ and $100 \mu M$ of egtazic acid.

Upon collection, all samples of medium $(50 \mu \mathrm{l})$ were centrifuged $(180 \times g, 7 \mathrm{~min})$ to remove floating cells from the medium. At the end of each experiment, cul- tures were examined by light microscopy to assess viability and this was quantitated by Trypan blue exclusion tests and lactate dehydrogenase assays (Sigma, procedure no. 500).

\section{Quinacrine staining}

Confluent HUVEC cultures on glass coverslips were rinsed several times in $\mathrm{DPBS}^{+}$. The cells were then incubated with quinacrine $(3 \mathrm{mM})$ for $60 \mathrm{~min}$ at room temperature, rinsed several times in $\mathrm{DPBS}^{+}$, and mounted on microscope slides. The cultures were then immediately observed using a microscope (Zeiss Axioplan, Zeiss, Oberkochen, Germany) fitted with a digital camera (Leica DC200; Leica, Heerbrugg, Switzerland).

To examine the effects of shear stress, endothelial cells were subjected to $25 \mathrm{dyn} / \mathrm{cm}^{2}$ for $60 \mathrm{~min}$ during the quinacrine incubation period. Inhibitor effects were investigated by simultaneous incubation with quinacrine ( 3 $\mathrm{m} M)$ and either monensin $\left(10^{-4} M\right)$ for 60 min or NEM $\left(10^{-6} M\right)$ for $15 \mathrm{~min}$.

\section{Measurement of adenosine triphosphate}

The quantity of ATP released in the medium was measured by luminometry using a luciferin-luciferase assay (15).

\section{Statistical analysis}

Concentrations of ATP were expressed as picomoles of ATP present per milliliter of medium. Results were compared by analysis of variance followed by Tukey test and were declared significantly different at $\mathrm{p}<0.05$; " $\mathrm{n}$ " refers to the number of umbilical cords (number of cell preparations) used.

\section{RESULTS}

Figure 1 shows that in the absence of any shear stress imposed on the endothelial cells, the concentration of ATP in the medium was very low and stable $(6.8 \pm 0.8$ $\mathrm{pmol} / \mathrm{ml})$. When a shear stress of $10 \mathrm{dyn} / \mathrm{cm}^{2}$ was imposed on the cells, there was an immediate and significant increase in the concentration of ATP in the medium. The maximum concentration was obtained after $3 \mathrm{~min}$ of stress $(42.3 \pm 1.9 \mathrm{pmol} / \mathrm{ml})$. The stimulation of the same endothelial cells with a shear stress of $25 \mathrm{dyn} / \mathrm{cm}^{2}$ led to the release of more ATP. The highest concentration of ATP was seen after 3 min of stress $(111.7 \pm 21.3$ $\mathrm{pmol} / \mathrm{ml}$ ) and gradually decreased to $11.5 \pm 2.6 \mathrm{pmol} / \mathrm{ml}$ after 60 min of shear stress.

After incubation of HUVEC primary cultures with quinacrine for $60 \mathrm{~min}$, a high level of fluorescence was seen inside all endothelial cells (Fig. 2A). This fluores- 


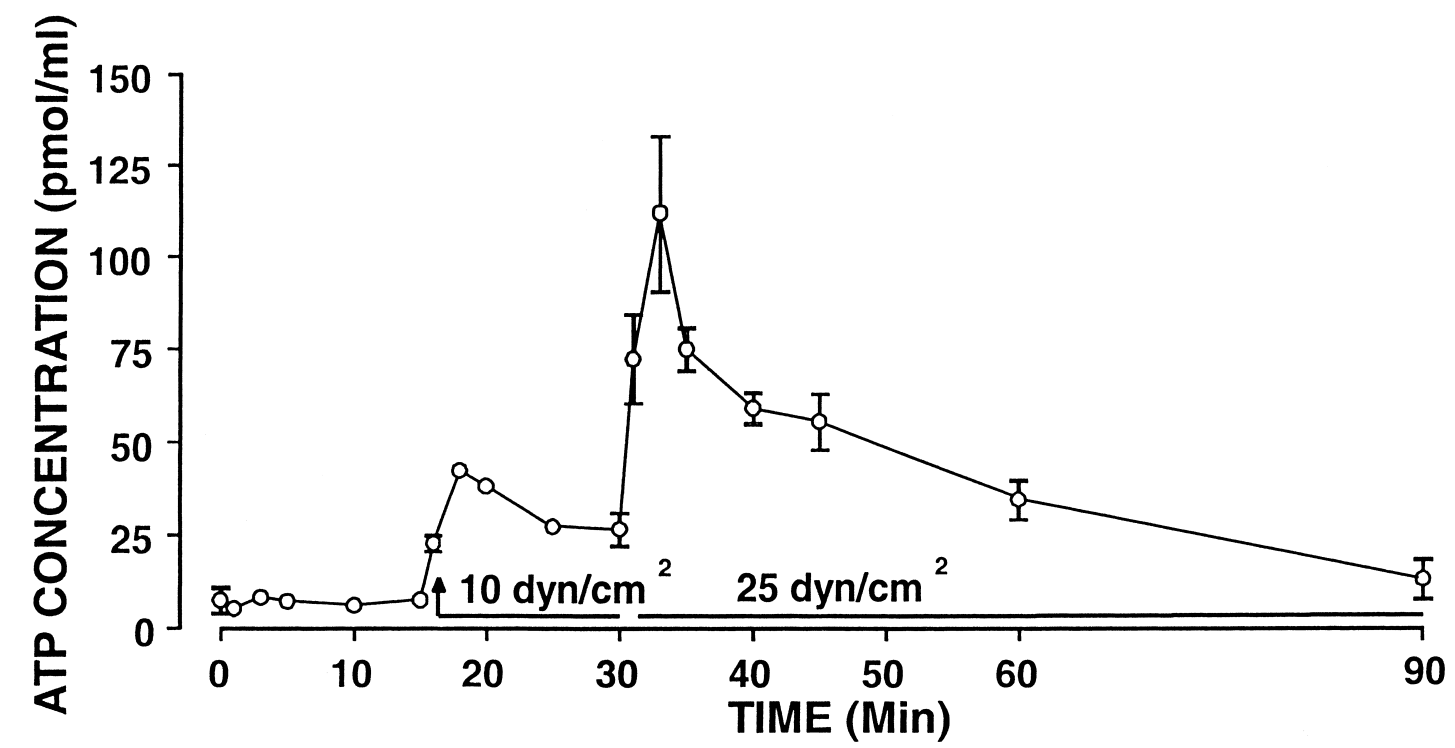

FIG. 1. Release of intracellular adenosine triphosphate (ATP) by endothelial cells under conditions of shear stress. Human umbilical vein endothelial cells in primary culture were placed in a cone and plate apparatus, left to rest, and subjected to two consecutive periods of shear stress of 10 and $25 \mathrm{dyn} / \mathrm{cm}^{2}$. ATP concentrations in the medium were measured by luminometry. The results are presented as the mean \pm SEM of four experiments.

cence was exclusively distributed within the cytoplasmic compartment. High magnification of the cells (Fig. 2B) shows that this fluorescence was mainly present in granular form. Under conditions of shear stress $(25$ $\mathrm{dyn} / \mathrm{cm}^{2}, 60 \mathrm{~min}$ ) the intracellular levels of quinacrine fluorescence were greatly reduced (Fig. 2C) and the fluorescent granules, still seen in some of the cells, appeared smaller than those present in the unstressed cells (Fig. 2D). After treatment with monensin $\left(10^{-4} M, 60 \mathrm{~min}\right)$, a drug that inhibits the formation of vesicles at the level of the Golgi apparatus, no fluorescent granular staining was detected within the cells (Fig. 2E). After treatment with NEM, $\left(10^{-6} M, 15 \mathrm{~min}\right)$, a drug that inhibits the docking of vesicles to plasma membranes, only a small loss of fluorescence was shown (Fig. 2F).

Monensin, at a concentration of $10^{-5} \mathrm{M}$, did not significantly affect the increase of ATP concentration resulting from stimulation of endothelial cells by shear stress (maximal concentration reached after $3 \mathrm{~min}$ of shear stress: control, $100 \% \pm 27 \%$; monensin-treated cultures, $78.2 \% \pm 19 \%, \mathrm{n}=5$ ). However, at a concentration of $10^{-4} M$ (Fig. 3), monensin produced a significant reduction in the shear stress-induced increase of extracellular ATP concentration (concentration of ATP after 5 min of shear stress: control, $100 \% \pm 34 \%$; monensintreated cultures, $22 \% \pm 6 \%, \mathrm{n}=4$ ).

The effects of NEM were investigated using concentrations of $10^{-6} \mathrm{M}$ and $10^{-5} \mathrm{M}$. At both concentrations used, there was a significant and almost complete inhi- bition of the increase in ATP concentration in the extracellular medium in the cultures stimulated by shear stress. Figure 4 shows the effects of NEM at a concentration of $10^{-6} M(14.8 \% \pm 3.7 \%$ of the control maximum, $\mathrm{n}=3$ ).

The role of extracellular $\mathrm{Ca}^{2+}$ in shear stress-evoked ATP release was investigated. Results are presented in Figure 5. In the absence of $\mathrm{Ca}^{2+}$ in the bathing medium, release of ATP was statistically reduced and only reached $46 \% \pm 9 \%(t=5 \mathrm{~min})$ of the maximum response seen in the control.

The effects of verapamil $\left(10^{-6}, 10^{-5}, 10^{-4} \mathrm{M}\right)$ were investigated on shear stress-evoked ATP release. No significant difference was found between the control and the verapamil-treated cells, at any of the concentrations tested. Figure $6 \mathrm{~A}$ presents the results obtained with the highest concentration of verapamil used. The effects of glibenclamide $\left(10^{-7}, 10^{-6}\right.$, and $\left.10^{-5} \mathrm{M}\right)$ were also investigated. This drug did not have any significant effect on the amount of ATP released by the endothelial cells. Figure 6A and $\mathrm{B}$ present the results obtained with the highest concentration of glibenclamide used.

\section{DISCUSSION}

On stimulation of HUVECs by laminar shear stress, intracellular ATP is released (16). This release is fast, 

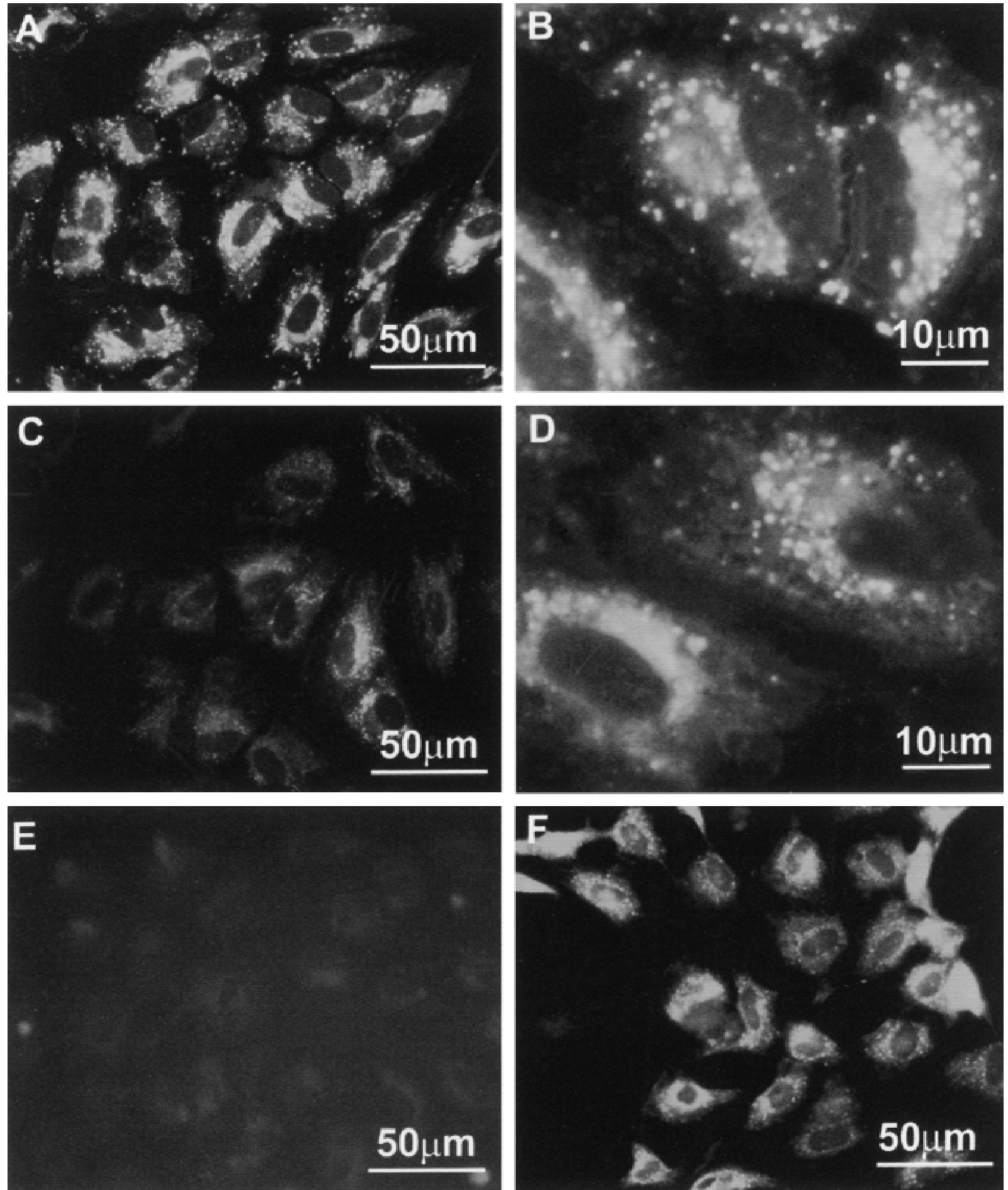

FIG. 2. Incubation of human umbilical vein endothelial cells (HUVECs) with quinacrine. A. A high level of fluorescence distributed within the cytoplasmic compartment was seen in all endothelial cells, indicative of intracellular stores of adenosine triphosphate (ATP). B. High magnification of the cells shows that this fluorescence is mainly distributed in granular vesicles. C. Under conditions of shear stress at $25 \mathrm{dyn} / \mathrm{cm}^{2}$, HUVECs display reduced intracellular levels of quinacrine fluorescence. D. High magnification of the cells under conditions of shear stress. The fluorescent granules appear smaller than in the untreated cells. E. After treatment with monensin $\left(10^{-4} \mathrm{M}\right)$ for $60 \mathrm{~min}$, no fluorescent granular staining was detected within the cells, only a faint, diffuse cytoplasmic staining. $\mathbf{F}$. After treatment with $N$ ethylmaleimide (NEM) $\left(10^{-6} \mathrm{M}\right)$ for $15 \mathrm{~min}$, only a small loss of fluoresence is visible. 


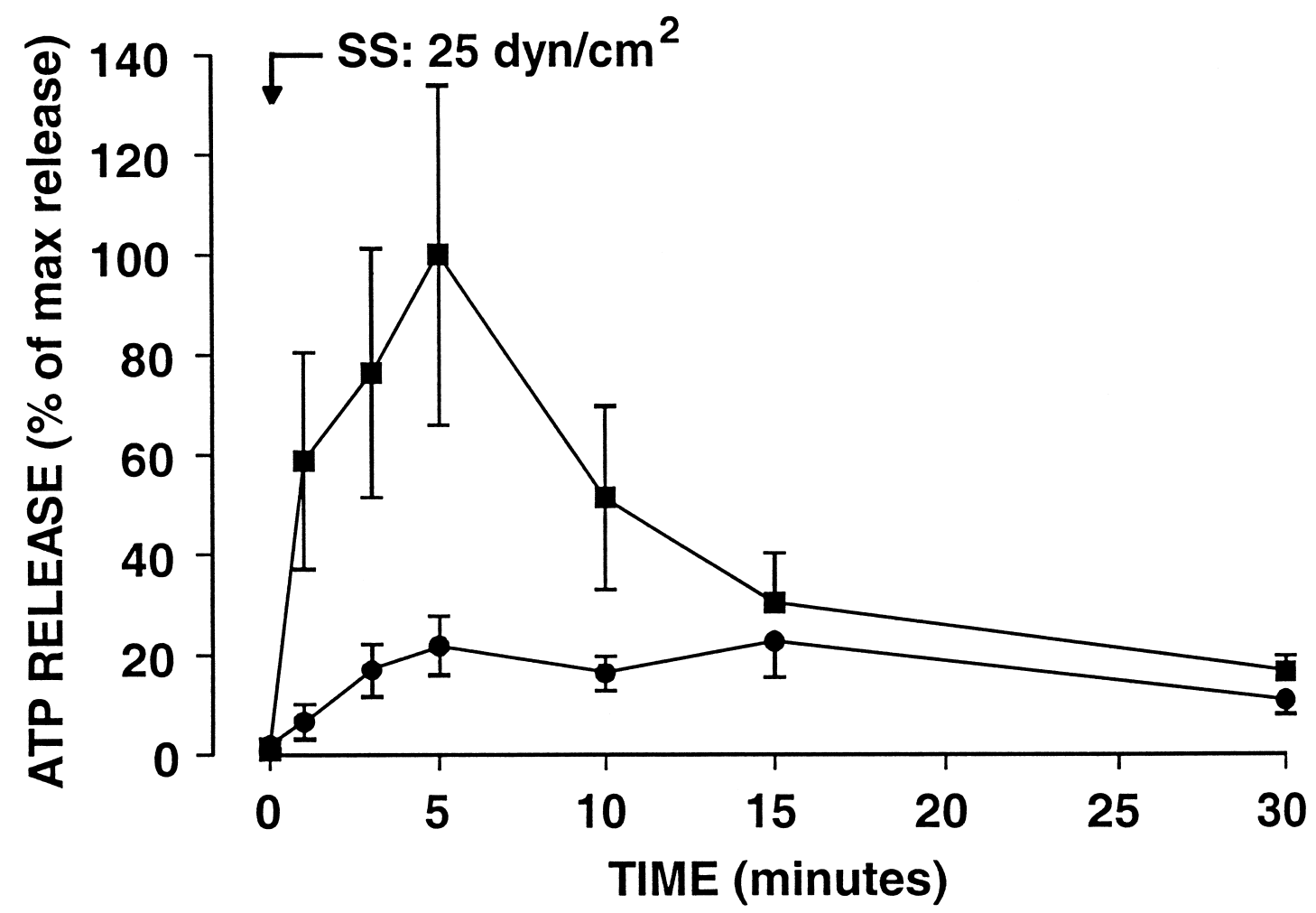

FIG. 3. Effects of monensin $\left(10^{-4} M\right)$ on the shear stress (SS)-induced increase in the concentration of extracellular adenosine triphosphate (ATP). Monensin was responsible for a significant drop in the SS-induced increase of extracellular ATP concentration compared with the control $(n=4)$. Results are presented as the means \pm SEM of the maximal release of ATP. Squares indicate control cells, circles indicate monensin-treated cells.

proportional to the intensity of the stress, and transient and decreases rapidly, probably through both depletion of intracellular ATP stores (4) and activation of ATPases and nucleotidases located on the surface of the cells (17). However, the mechanisms of release of ATP from endothelial cells are not known.

Because of its high affinity for ATP, quinacrine, an anti-malarial acridine derivative that belongs to the quinoline-acridine class, has been widely used to locate possible intracellular stores of the purine $(18,19)$. A link between quinacrine binding and neural purinergic transmission has been demonstrated in both vertebrates $(20$ 22) and invertebrates (23). Quinacrine labeling has also been used to localize ATP in peripheral cells such as Merkel cells (24) and epithelial cells (25).

In HUVECs, quinacrine fluorescence appeared granular and exclusively localized in the cytoplasm. Under conditions of shear stress $\left(25 \mathrm{dyn} / \mathrm{cm}^{2}, 60 \mathrm{~min}\right)$, the intracellular levels of quinacrine fluorescence were greatly reduced and the fluorescent granules, still seen in some of the cells, appeared smaller than those present in the unstressed cells. After treatment with monensin, a drug that suppresses the formation of vesicles at the level of the Golgi apparatus (10) and thus inhibits vesicular release (26), there was also a dramatic decrease in the granular quinacrine fluorescence for ATP inside the cells, being replaced by a faint diffuse intracellular fluorescence. Conversely, treatment with NEM resulted in only a small loss of fluorescence. Considering that NEM is a drug that inhibits vesicular release by acting on an NEM-sensitive factor required for the fusion of vesicles to plasma membranes (11), the presence of fluorescence inside the cells would be expected.

Release of ATP under conditions of increased shear stress was measured in the presence of monensin. Under these experimental conditions, there was a complete inhibition of release. The effects of NEM were investigated and confirmed the results obtained previously with monensin. We are, of course, aware of the non-specificity of these two drugs and of the broad range of cellular actions of monensin as a monovalent ion-selective ionophore $(10,26)$ and of NEM as a potent alkylating agent $(27)$. However, to our knowledge, the inhibition of vesicular transport is the sole property that these drugs have in common. Moreover, because these two drugs act at two different levels by two different mechanisms, it is un- 


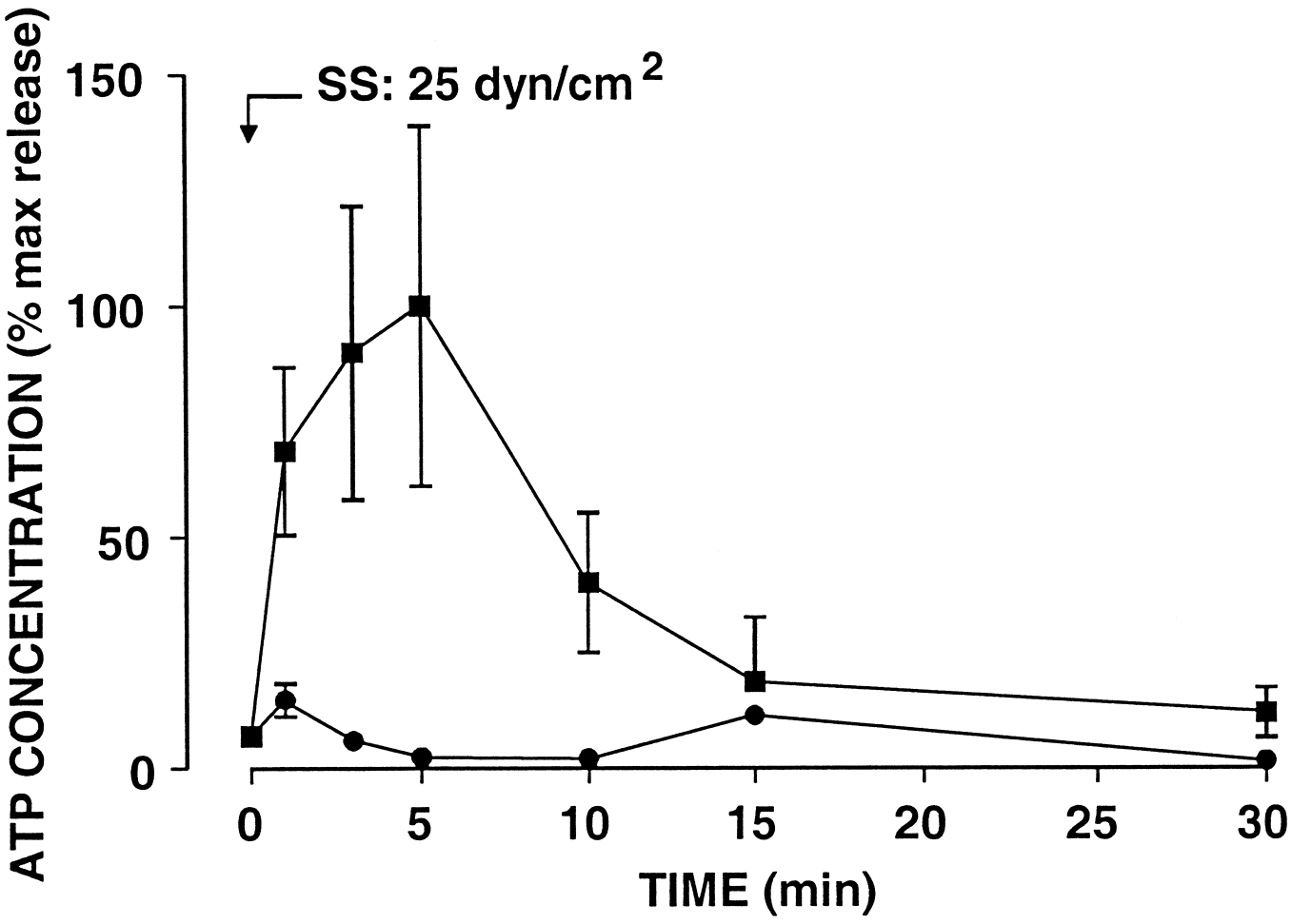

FIG. 4. Effects of $N$-ethylmaleimide (NEM) on the shear stress (SS)-induced accumulation of extracellular adenosine triphosphate (ATP) in the culture medium. When human umbilical vein endothelial cell (HUVEC) cultures were preincubated with NEM $\left(10^{-6} M\right)$, there was a significant inhibition $(p<0.001)$ of the increase of ATP concentration in the extracellular medium compared with control. Results are presented as means \pm SEM of the maximal release of ATP $(n=3)$. Squares indicate control cells; circles indicate NEM-treated cells.

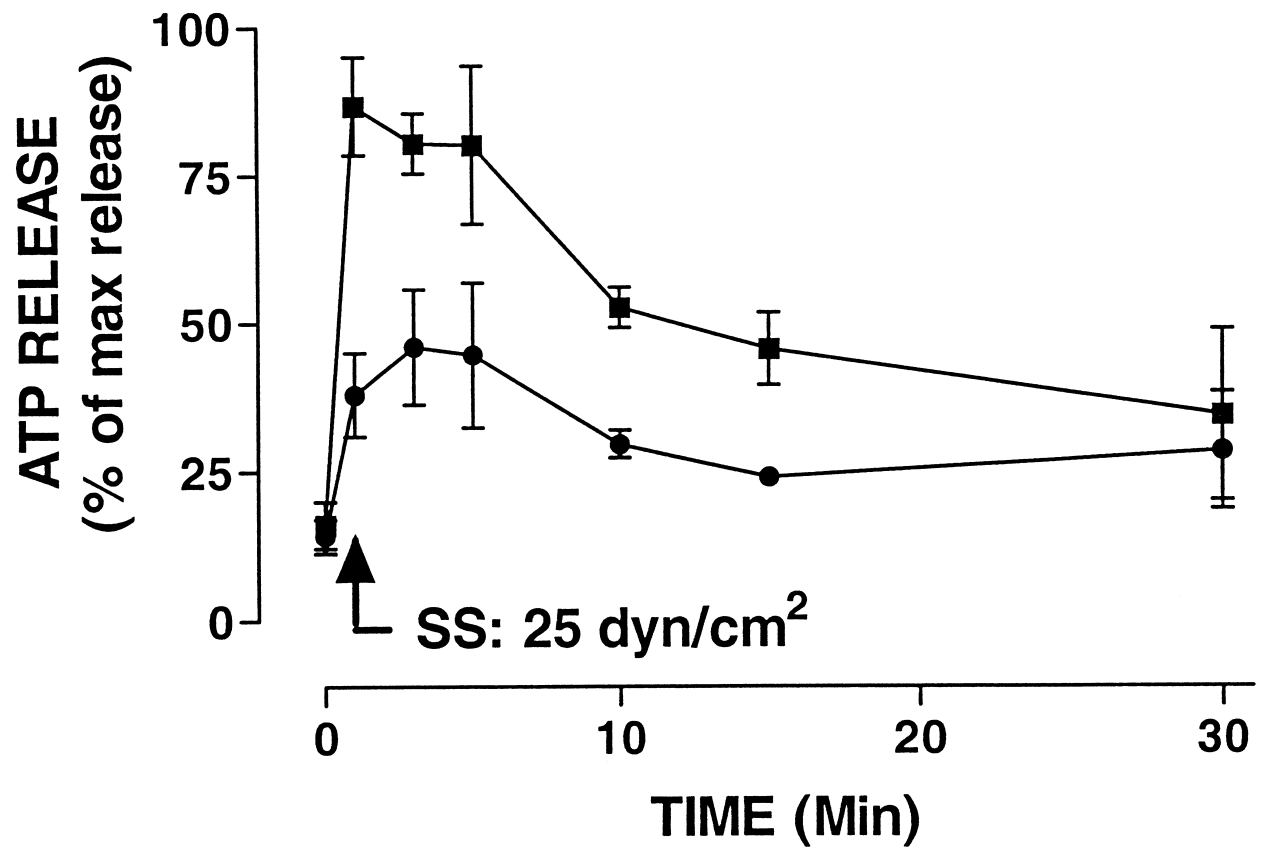

FIG. 5. Effects of extracellular $\mathrm{Ca}^{2+}$ on shear stress-evoked adeonsine triphosphate (ATP) release by human umbilical vein endothelial cells (HUVECs). The release of ATP was statistically reduced in $\mathrm{Ca}^{2+}$-free medium, and only reached $46 \% \pm 9 \%$ of the maximum response seen in the control. Squares indicate control; circles indicate $\mathrm{Ca}^{2+}{ }_{\text {-free }}$ medium. 


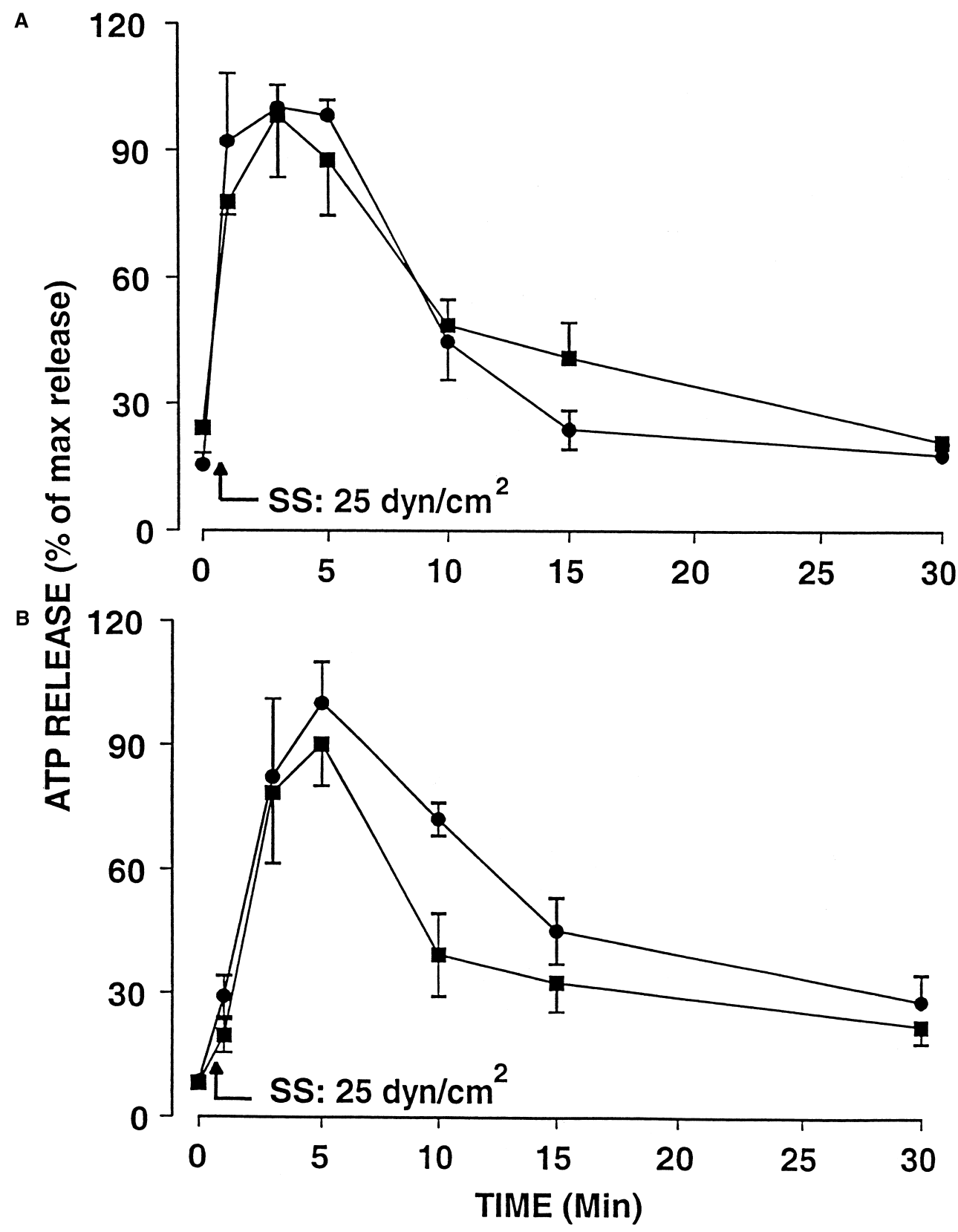

FIG. 6. A. Verapamil $\left(10^{-4} \mathrm{M}\right)$ did not significantly affect the increase in extracellular adenosine triphosphate (ATP) concentration evoked by shear stress (SS). Squares indicate control cells; circles indicate verapamil-treated cells $(\mathrm{n}=4)$. B. Glibenclamide $\left(10^{-5} M\right)$ did not significantly change the amount of ATP released by the cells $(n=4)$. Squares indicate control cells; circles indicate glibenclamidetreated cells. Results are presented as means \pm SEM of the maximal release of ATP.

likely that their respective effects on the inhibition of vesicular transport were due to nonspecific effects.

On the basis of the results obtained by two different approaches, it may be considered that in endothelial cells, ATP is present in the cytoplasmic vesicles known to exist in endothelial cells and is released on stimulation of the cells by increased shear stress. In the absence of extracellular $\mathrm{Ca}^{2+}$, however, we found that ATP release still occurs, though it is significantly reduced. It should be noted that removal of all extracellular $\mathrm{Ca}^{2+}$ from cultures is extremely difficult because increasing numbers of cells detach from the substratum under conditions of shear stress at high concentrations of egtazic acid or in $\mathrm{Ca}^{2+}$-deficient medium. It is thus possible that extracel- 
lular $\mathrm{Ca}^{2+}$ is still present at a concentration sufficient for vesicular release to occur. In addition, some cells may be damaged in the absence of extracellular $\mathrm{Ca}^{2+}$, leading to a non-specific release of intracellular ATP. Yet a further possibility is that ATP can also be released by a mechanism independent of extracellular $\mathrm{Ca}^{2+}$.

Adenosine triphosphate-binding cassette proteins are part of a family of proteins sharing a common intracellular motif that binds and hydrolyzes ATP (7). Furthermore, it has been shown that these proteins are able to transfer ATP itself. For instance, CFTR, a cyclic adenosine monophosphate-activated ATP-dependent $\mathrm{Cl}^{-}$ channel, conducts ATP at rates that can be measured electrophysiologically (28). P-glycoprotein or MDR is also capable of functioning as a channel transporting both $\mathrm{Cl}^{-}$and ATP out of the cell (29). These two ABC proteins and the sulfonylurea receptor, another $A B C$ transporter that is an ATP-sensitive $\mathrm{K}^{+}$channel, have been identified on vascular endothelial cells (12-14). However, the role of these $\mathrm{ABC}$ proteins in the direct transport across membranes is still unclear, and it has been demonstrated that purified CFTR does not function as an ATP transporter (30). Nevertheless, this does not mean that $\mathrm{ABC}$ proteins are unable to translocate ATP across membranes. It is conceivable that $\mathrm{ABC}$ proteins are part of a heterogeneous complex responsible for the movement of ATP, and the expression of a cofactor or a regulatory protein could be essential for the ATP channel activity to occur. It is already known that CFTR forms a complex with a chloride channel whereas the sulfonylurea receptor interacts with an ATP-regulated potassium channel to be able to carry out ATP $(31,32)$. It is also possible that $\mathrm{ABC}$ proteins regulate other release mechanisms such as exocytosis (9).

In our preliminary study, the involvement of these $\mathrm{ABC}$ proteins in the transport of ATP from vascular endothelial cells was investigated by incubation with glibenclamide, an inhibitor of both the sulfonylurea receptor and CFTR $(33,34)$, and verapamil, an inhibitor of MDR (35). Our results show that these inhibitors had no effect on the shear stress-induced release of ATP from HUVECs. There could be several reasons for this: e.g., the role of these $\mathrm{ABC}$ proteins in the direct transport of ATP across membranes is still debated and it has been shown that purified CFTR does not function as an ATP transporter (30). However, it should be emphasized that these proteins could still participate indirectly in ATP transport as part of a heterogeneous molecular complex. Cells in culture could also change their phenotype and lose their ability to synthesize $\mathrm{ABC}$ proteins or the associated ATP transporters. Finally, results were obtained using HUVECs in this study and differences could exist in endothelial cells from other vascular beds or from microvascular vessels (36).

Taken together, the results from this study suggest a vesicular release of ATP from endothelial cells under conditions of increased shear stress and suggest that CFTR, MDR, and the sulfonylurea receptor may not be involved in the transport of ATP. However, the results do not exclude the participation of these $\mathrm{ABC}$ proteins or other members of this family in the transport of ATP following other chemical or mechanical stimuli.

Acknowledgment: This work was supported by the British Heart Foundation. The authors thank the nurses of the Obstetric Board of the Royal Free Hospital, London, for providing the umbilical cords.

\section{REFERENCES}

1. Dewey CF Jr, Bussolari SR, Gimbrone MA Jr, et al. The dynamic response of vascular endothelial cells to fluid shear stress. J Biomech Eng 1981;103:177-85.

2. Bodin P, Loesch A, Milner P, et al. Effect of increased flow on release of vasoactive substances from vascular endothelial cells. In: Lyall F, El Haj AJ, eds. Biomechanics and cells: part I: soft tissue (The Society of Experimental Biology Seminar Series 54). Cambridge: Cambridge University Press, 1994:37-60.

3. Dimmeler S, Hermann C, Galle J, et al. Upregulation of superoxide dismutase and nitric oxide synthase mediates the apoptosis-suppressive effects of shear stress on endothelial cells. Arterioscler Thromb Vasc Biol 1999;19: 656-64.

4. Bodin P, Bailey DJ, Burnstock G. Increased flow-induced ATP release from isolated vascular endothelial but not smooth muscle cells. Br J Pharmacol 1991;103:1203-5.

5. Burnstock G, ed. Purinergic neurotransmission. Semin Neurosci 1996;8:171-257.

6. Bodin P, Burnstock G. Purinergic signalling: ATP release. Neurochem Res 2001 (in press).

7. Demolombei S, Escande D. ATP-binding cassette proteins as targets for drug discovery. Trends Pharmacol Sci 1996; $17: 273-5$.

8. Roman RM, Wang Y, Lidofsky SD, et al. Hepatocellular ATP-binding cassette protein expression enhances ATP release and autocrine regulation of cell volume. J Biol Chem 1997;272:21970-6.

9. Schwiebert EM. ABC transporter-facilitated ATP conductive transport. Am J Physiol 1999;276:C1-8.

10. Cecchelli R, Cacan R, Porchet-Hennere E, et al. Dilatation of Golgi vesicles by monensin leads to enhanced accumulation of sugar nucleotides. Biosci Rep 1986;6:227-34.

11. Block MR, Glick BS, Wilcox CA, et al. Purification of an $\mathrm{N}$-ethylmaleimide-sensitive protein catalyzing vesicular transport. Proc Natl Acad Sci U S A 1988;85:7852-6.

12. Cordon-Cardo C, O'Brien JP, Casals D, et al. Multidrugresistance gene (P-glycoprotein) is expressed by endothelial cells at blood-brain barrier sites. Proc Natl Acad Sci U S A 1989;86:695-8. 
13. Katnik C, Adams DJ. An ATP-sensitive potassium conductance in rabbit arterial endothelial cells. J Physiol (Lond) 1995;485:595-606.

14. Tousson A, Van Tine BA, Naren AP, et al. Characterization of CFTR expression and chloride channel activity in human endothelia. Am J Physiol 1998;275:C1555-64.

15. Bodin P, Burnstock G. Synergistic effect of acute hypoxia on flow-induced release of ATP from cultured endothelial cells. Experientia 1995;51:256-9.

16. Bodin P, Burnstock G. Increased release of ATP from endothelial cells during acute inflammation. Inflamm Res 1998;47:351-4.

17. Yegutkin GG, Burnstock G. Inhibitory effects of some purinergic agents on ecto-ATPase activity and pattern of stepwise ATP hydrolysis in rat liver plasma membranes. Biochim Biophys Acta 2000;1466:234-44.

18. Irvin JL, Irvin EM. The interaction of quinacrine with adenine nucleotides. J Biol Chem 1954;210:45-56.

19. Olson L, Ålund M, Norberg KA. Fluorescencemicroscopical demonstration of a population of gastrointestinal nerve fibers with a selective affinity for quinacrine. Cell Tissue Res 1976;171:407-23.

20. Burnstock G, Cocks T, Crowe R, et al. Purinergic innervation of the guinea-pig urinary bladder. $\mathrm{Br} J$ Pharmacol 1978;63:125-38.

21. Ålund M, Olson L. Depolarization-induced decreases in fluorescence intensity of gastro-intestinal quinacrinebinding nerves. Brain Res 1979;166:121-37.

22. Crowe R, Burnstock G. Comparative studies of quinacrinepositive neurones in the myenteric plexus of stomach and intestine of guinea-pig, rabbit and rat. Cell Tissue Res 1981;221:93-107.

23. Knight GE, Hoyle CHV, Burnstock G. Quinacrine-staining of neurones, and activity of purine nucleosides and nucleotides in marine and terrestrial invertebrates from several phyla. Comp Biochem Physiol 1992;102C:305-14.

24. Crowe R, Whitear M. Quinacrine fluorescence of Merkel cells in Xenopus laevis. Cell Tissue Res 1978;190:273-83.

25. Mitchell CH, Carré DA, McGlinn AM, et al. A release mechanism for stored ATP in ocular ciliary epithelial cells. Proc Natl Acad Sci U S A 1998;95:7174-8.
26. Mollenhauer HH, Morre DJ, Rowe LD. Alteration of intracellular traffic by monensin: mechanism, specificity and relationship to toxicity. Biochim Biophys Acta 1990;1031: 225-46.

27. Freed BM, Lempert N, Lawrence DA. The inhibitory effects of N-ethylmaleimide, colchicine and cytochalasins on human T-cell functions. Int J Immunopharmacol 1989;11: 459-65.

28. Reisin IL, Prat AG, Abraham EH, et al. The cystic fibrosis transmembrane conductance regulator is a dual ATP and chloride channel. J Biol Chem 1994;269:20584-91.

29. Valverde MA, Diaz M, Sepulveda FV, et al. Volumeregulated chloride channels associated with the human multidrug-resistance P-glycoprotein. Nature 1992;355: 830-3.

30. Li C, Ramjeesingh M, Bear CE. Purified cystic fibrosis transmembrane conductance regulator (CFTR) does not function as an ATP channel. J Biol Chem 1996;271: 11623-6.

31. Guidotti G. ATP transport and ABC proteins. Chem Biol 1996;3:703-6.

32. Sugita M, Yue Y, Foskett JK. CFTR $\mathrm{Cl}^{-}$channel and CFTR-associated ATP channel: distinct pores regulated by common gates. EMBO J 1998;17:898-908.

33. Fosset M, de Weille JR, Green RD, et al. Antidiabetic sulfonylureas control action potential properties in heart cells via high affinity receptors that are linked to ATPdependent $\mathrm{K}^{+}$channels. J Biol Chem 1988;263:7933-6.

34. Sheppard DN, Welsh MJ. Effect of ATP-sensitive $\mathrm{K}^{+}$ channel regulators on cystic fibrosis transmembrane conductance regulator chloride currents. J Gen Physiol 1992; 100:573-91.

35. Cano-Gauci DF, Riordan JR. Action of calcium antagonists on multidrug resistant cells: specific cytotoxicity independent of increased cancer drug accumulation. Biochem Pharmacol 1987;36:2115-23.

36. Iwahana M, Utoguchi N, Mayumi T, et al. Drug resistance and P-glycoprotein expression in endothelial cells of newly formed capillaries induced by tumors. Anticancer Res 1998;18:2977-80. 